OPEN ACCESS

Edited by:

Robert Petersen

Central Michigan University,

United States

Reviewed by:

Luis C. Romero,

Institute of Plant Biochemistry and

Photosynthesis (IBVF), Spain

Safikur Rahman,

Babasaheb Bhimrao Ambedkar Bihar

University, India

*Correspondence:

Milos R. Filipovic

milos.filipovic@isas.de

Received: 28 February 2021 Accepted: 24 May 2021

Published: 23 June 2021

Citation:

Petrovic D, Kouroussis E, Vignane T and Filipovic MR (2021) The Role of Protein Persulfidation in Brain Aging and Neurodegeneration.

Front. Aging Neurosci. 13:674135.

doi: 10.3389/fnagi.2021.674135

\section{The Role of Protein Persulfidation in Brain Aging and Neurodegeneration}

\author{
Dunja Petrovic, Emilia Kouroussis, Thibaut Vignane and Milos R. Filipovic*
}

Leibniz-Institut für Analytische Wissenschaften - ISAS - e.V., Dortmund, Germany

Hydrogen sulfide $\left(\mathrm{H}_{2} \mathrm{~S}\right)$, originally considered a toxic gas, is now a recognized gasotransmitter. Numerous studies have revealed the role of $\mathrm{H}_{2} \mathrm{~S}$ as a redox signaling molecule that controls important physiological/pathophysiological functions. The underlying mechanism postulated to serve as an explanation of these effects is protein persulfidation (P-SSH, also known as S-sulfhydration), an oxidative posttranslational modification of cysteine thiols. Protein persulfidation has remained understudied due to its instability and chemical reactivity similar to other cysteine modifications, making it very difficult to selectively label. Recent developments of persulfide labeling techniques have started unraveling the role of this modification in (patho)physiology. PSSH levels are important for the cellular defense against oxidative injury, albeit they decrease with aging, leaving proteins vulnerable to oxidative damage. Aging is one of the main risk factors for many neurodegenerative diseases. Persulfidation has been shown to be dysregulated in Parkinson's, Alzheimer's, Huntington's disease, and Spinocerebellar ataxia 3. This article reviews the latest discoveries that link protein persulfidation, aging and neurodegeneration, and provides future directions for this research field that could result in development of targeted drug design.

Keywords: persulfidation, neurodegenerative disease, aging, hydrogen sulfide, redox signaling

\section{INTRODUCTION}

Hydrogen sulfide $\left(\mathrm{H}_{2} \mathrm{~S}\right)$ is a small colorless gas that has sparked large controversy over the past two decades. Before the discovery that eukaryotes synthesize $\mathrm{H}_{2} \mathrm{~S}$ and the recognition that it has a physiological purpose, for hundreds of years, $\mathrm{H}_{2} \mathrm{~S}$ was viewed solely as a toxic gas released into the atmosphere by volcanic eruptions and utilized by bacteria and microbes. However, it was $\mathrm{H}_{2} \mathrm{~S}$ that was used, together with cyanide and UV-light, to synthesize the building blocks of life such as RNA, lipids and nucleic acids (Patel et al., 2015) and early life forms thrived in $\mathrm{H}_{2} \mathrm{~S}$-rich environment for hundreds of millions of years (Olson and Straub, 2016). The recognition of the physiological importance of $\mathrm{H}_{2} \mathrm{~S}$ started to emerge from the first report by Abe and Kimura, identifying that $\mathrm{H}_{2} \mathrm{~S}$ is a neurological modulator in the brain (Abe and Kimura, 1996), stimulating a productive two decades of research.

There are three main enzymes involved in $\mathrm{H}_{2} \mathrm{~S}$ formation. Two of the enzymes are pyridoxal $5^{\prime}$-phosphate (PLP)-dependent enzymes, cystathionine $\beta$-synthase (CBS), and cystathionine $\gamma$ lyase (CSE; also known as CTH) important for the transsulfuration pathway. These enzymes are predominantly located in the cytosol; however, their presence in other compartments, such as the nucleus and mitochondria, has been reported (Kabil et al., 2006; Fu et al., 2012; Teng et al., 2013). The third enzyme is the PLP-independent, 3-mercaptopyruvate sulfurtransferase (MST; also known as MPST), located in the mitochondria and the cytoplasm (Figure 1A) (Nagahara et al., 1998). In 


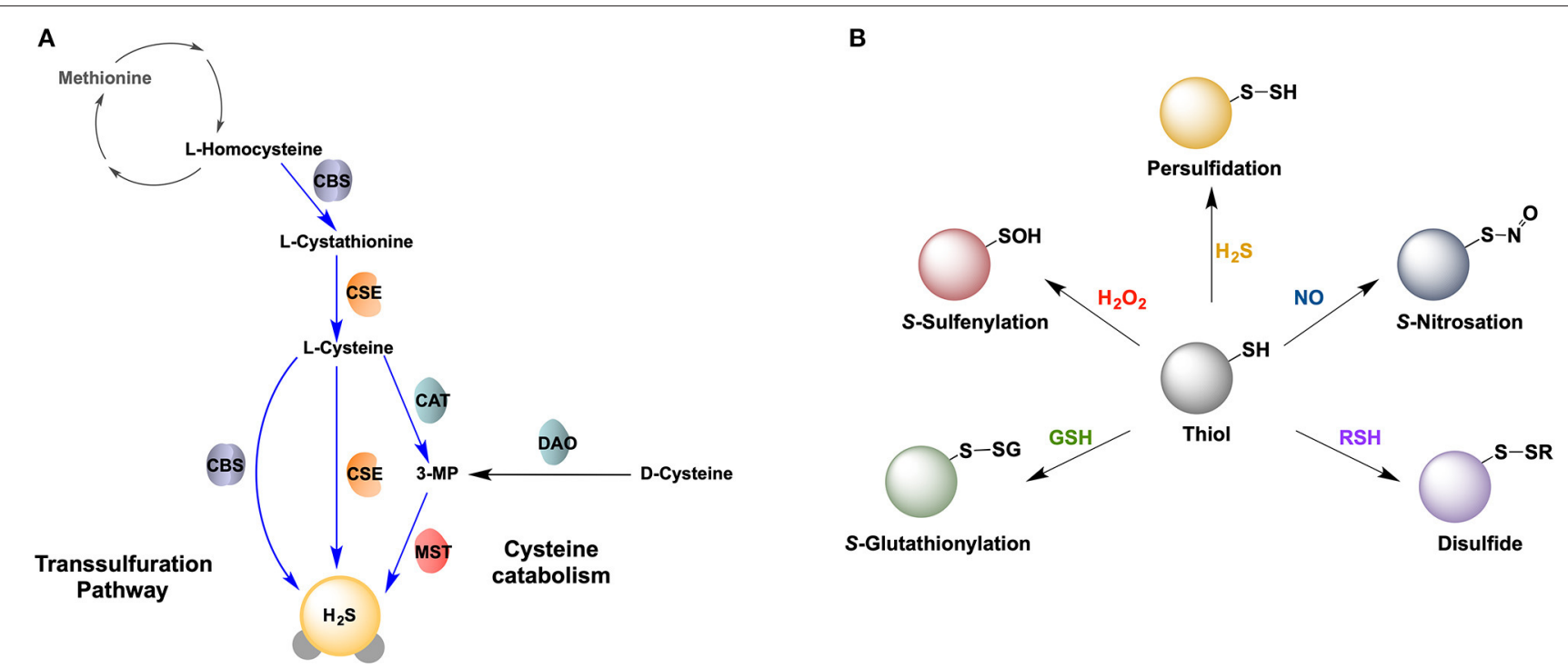

C

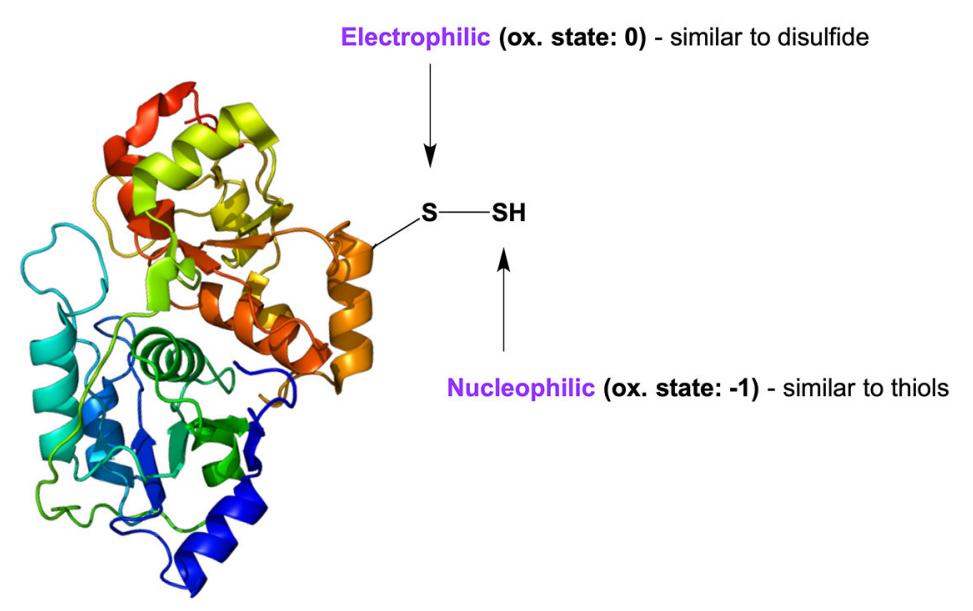

FIGURE 1 | Hydrogen sulfide and protein persulfidation. (A) Biosynthesis of $\mathrm{H}_{2} \mathrm{~S}$ via transsulfuration pathway and cysteine catabolism. CBS: cystathionine beta synthase; CSE, cystathionine gamma lyase; CAT, cysteine aminotransferase; DAO, D-amino acid oxidase; MST, mercaptopyruvate sulfur transferase. (B) Reversible posttranslational modifications of cysteine. (C) Dual chemical nature of protein persulfides, with one sulfur atom being electrophilic and the other nucleophilic.

the central nervous system (CNS), CBS is predominantly expressed in glial cells, while CSE is the main contributor of $\mathrm{H}_{2} \mathrm{~S}$ production in neurons. MST is widely distributed in all cell types (Paul et al., 2014; Zivanovic et al., 2019).

The reactivity of $\mathrm{H}_{2} \mathrm{~S}$ in biological systems can be divided into three groups: (i) reaction with/scavenging of reactive oxygen and reactive nitrogen species (ROS and RNS); (ii) binding to and/or subsequent redox reactions with metal centers; and (iii) reaction with proteins, herein called persulfidation (alternatively, S-sulfhydration) (Filipovic et al., 2018).

Numerous physiological functions have been shown to exclusively or partly be regulated by $\mathrm{H}_{2} \mathrm{~S}$, some of which being vasodilation (Yang et al., 2008; Szijártó et al., 2018), neurotransmission (Abe and Kimura, 1996), angiogenesis (Szabó and Papapetropoulos, 2011), inflammation (Whiteman and Winyard, 2011), and hypoxia sensing (Peng et al., 2014). Additionally, $\mathrm{H}_{2} \mathrm{~S}$ has been shown to induce a suspended animation-like state in mice (Blackstone et al., 2005). Furthermore, $\mathrm{H}_{2} \mathrm{~S}$ shows a tremendous pharmacological potential (Szabõ, 2007; Wallace and Wang, 2015); with a quick search on Pubmed suggesting that $\mathrm{H}_{2} \mathrm{~S}$ has a potential of curing almost every disease. Several pharmacological donors of $\mathrm{H}_{2} \mathrm{~S}$ have also been developed with hope of their eventual use in disease treatment (Wallace and Wang, 2015; Whiteman et al., 2015), but the question of how $\mathrm{H}_{2} \mathrm{~S}$ acts to alleviate all of the aforementioned diseases remains a hot topic of research. 


\section{PROTEIN PERSULFIDATION}

\section{Persulfide Biochemistry}

Snyder's group proposed that the main mechanism for $\mathrm{H}_{2} \mathrm{~S}$ signaling is a new oxidative post-translational modification of protein cysteine residues (P-SH), S-sulfhydration (or persulfidation, P-SSH) (Mustafa et al., 2009; Paul and Snyder, 2012, 2015). Persulfidation has been proposed to represent a new type of redox-switch reaction responsible for the regulation of protein structure and function (Figure 1B), alongside $S$-nitrosation (P-SNO), S-glutahtionylation (P-SSG), and $S$-sulfenylation (P-SOH).

Protein persulfidation has become increasingly recognized as the main mechanism by which $\mathrm{H}_{2} \mathrm{~S}$ controls cellular functions. The persulfide group is a type of unsymmetrical disulfide, bearing two sulfur atoms with different properties (Figure 1C). Its inner sulfur; P-SSH is considered a sulfane sulfur with an oxidation state of 0 , having a slightly electrophilic nature (thus, susceptible to nucleophilic attack) (Filipovic, 2015; Filipovic et al., 2018). However, its outer sulfur; P-SSH, has an oxidation state of -1 making it nucleophilic (thus, can react with electrophiles). P$\mathrm{SSH}$ is ionisable and acidic, existing predominantly in its anionic form, P-SS $^{-}$at physiological pH 7.4 (Cuevasanta et al., 2015). Its fully ionized nature, coupled with an alpha effect from its adjacent sulfur, makes it a much stronger nucleophile (and thus more reactive) compared to its corresponding thiol (Cuevasanta et al., 2015; Filipovic et al., 2018). The nucleophilicity of persulfides renders them reactive to 1 - and 2- electron oxidants (Cuevasanta et al., 2017; Filipovic et al., 2018).

One common misconception is that persulfides are formed via a direct reaction of $\mathrm{H}_{2} \mathrm{~S}$ and a cysteine thiolate. However, this reaction is thermodynamically unfavorable and the effects claimed to be by "direct" protein persulfidation produced by treating proteins with $\mathrm{H}_{2} \mathrm{~S}$ solutions have been assigned to the impurities in those solutions (Kimura et al., 2013; Wedmann et al., 2014; Zhang et al., 2014). The main mechanisms by which persulfides are non-enzymatically formed are through reactions of $\mathrm{H}_{2} \mathrm{~S}$ with oxidized cysteines, such as $\mathrm{P}-\mathrm{SOH}$ (Cuevasanta et al., 2015; Zivanovic et al., 2019), disulfides (Cuevasanta et al., 2015; Vasas et al., 2015), or in reactions of cysteine residues with sulfide radicals (Vitvitsky et al., 2018), polysulfides (Greiner et al., 2013), and other persulfides (so called transpersulfidation) (Ida et al., 2014). In addition, metalloproteins with iron or zinc in the active site could serve as catalysts for persulfide formation (Vitvitsky et al., 2018; Lange et al., 2019).

Persulfidation is considered to be a reversible modification and given the increasing evidence of its prominent signaling role, its endogenous removal is essential. Two parallel studies showed that the thioredoxin/thioredoxin reductase system efficiently reduces persulfides restoring the cysteine residue (Dóka et al., 2016; Wedmann et al., 2016). This "depersulfidase" activity has been observed in both cells and humans.

\section{Persulfide Detection}

Although persulfides might appear as "one sulfur away" from regular thiols, it is this exact feature that makes them very reactive (Yadav et al., 2016) and difficult to label, which explains why this field still remains understudied despite persulfides widespread distribution. Several methods for persulfide detection have been proposed (Figure 2).

The first method described for the detection of persulfides was the modified biotin switch method (Mustafa et al., 2009) (Figure 2A). However, the selectivity of this approach was questioned due to the fact that persulfides are more reactive than thiols (Cuevasanta et al., 2015) and can readily react with methanethiosulfonate, as demonstrated by Pan and Carroll (Pan and Carroll, 2013).

The blocking of P-SSH with electrophiles, followed by its reduction was proposed originally by Snyder's group. The authors used fluorescently labeled maleimide to block thiols and persulfides and by comparing the intensity of the signal obtained with or without dithiothreitol (DTT) they calculated the yield of P-SSH (Sen et al., 2012) (Figure 2B). A modification of this approach was used by Cuevasanta et al. (2015) and Gao et al. (2015) to detect persulfides by Mass spectrometry (MS), and other modifications have been also reported (Dóka et al., 2016; Longen et al., 2016). While the approach is reliable when working with purified proteins, the method suffers from the lack of selectivity when applied on cell extracts (Fan et al., 2020).

An improvement to this approach and currently the only "direct" method for persulfide detection has been recently proposed by Yang's group (Fu et al., 2020), known as low-pH Quantitative Thiol Reactivity Profiling (QTRP). Alkylation is performed at a low $\mathrm{pH}$ to keep persulfides fully deprotonated and highly reactive, and the majority of free thiols protonated and less reactive. Using click chemistry and UV-cleavable biotinylated probes for peptide release, the authors cleverly avoided the reduction step and directly compared the $m / z$ of peptides whilst taking into account the presence of additional sulfur in persulfide-containing peptides (Figure 2C).

The Tag-switch method proposed by Zhang et al. (2014) is based on a different chemical approach where thiols and persulfides are blocked with an aromatic thiol blocking reagent. In the case of persulfides this results in the formation of an activated disulfide bond; with different properties to endogenous disulfides and readily susceptible to specific nucleophiles tags (Zhang et al., 2014; Yadav et al., 2016; Aroca et al., 2017). An improvement of this method was recently published, named the Dimedone-switch method (Zivanovic et al., 2019) where commercially available dimedone-based probes were used as the nucleophilic tags (Figure 2D). The method proved to be very robust and versatile for any persulfide-detecting use.

Since the (bio)chemistry of $\mathrm{H}_{2} \mathrm{~S}$ and protein persulfidation has been covered elsewhere (Filipovic, 2015; Paul and Snyder, 2015; Cuevasanta et al., 2017; Filipovic et al., 2018) in much more detail, we will focus on providing an overview of the role of protein persulfidation in the aging of the brain, with particularly emphasis on its role(s) in neurodegeneration.

\section{RELATIONSHIP BETWEEN $\mathrm{H}_{2}$ S/PROTEIN PERSULFIDATION AND AGING}

The aging process is a progressive loss of physiological function which emerges when an organism grows older. This process results from a time-dependant accumulation of cellular damage 
A<smiles>CSSc1ccccc1-c1cccc(SSSc2ccccc2)c1</smiles>

B

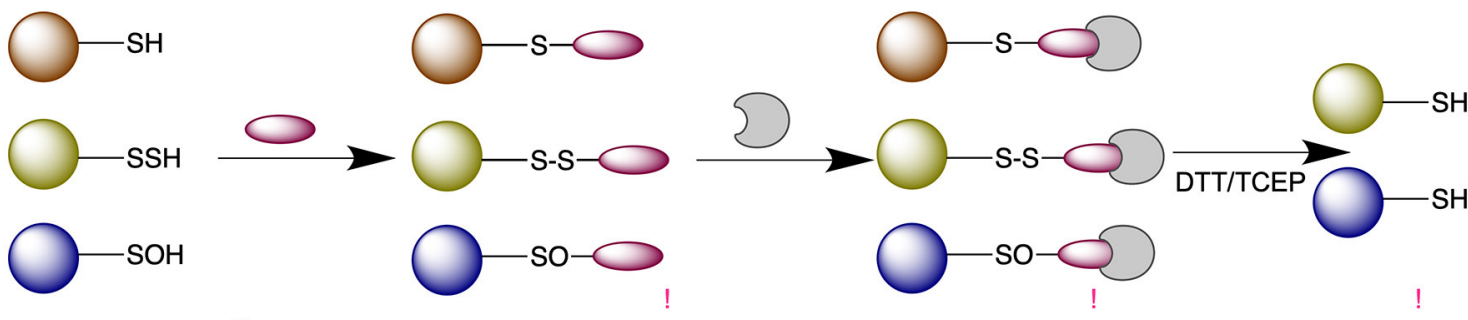
$O=O_{0}$

C<smiles>C#CCNC(=O)CSc1ccccc1SCC(=O)NCC#CCNC(=O)CI</smiles><smiles>N#CCCCCCC(=O)OC(C(=O)O)C(=O)OCCNC(=O)COc1cccc(C(=O)OCc2ccccc2)c1</smiles>

D<smiles>SC1CCCCCC1</smiles><smiles>[Os]Sc1ccccc1</smiles>
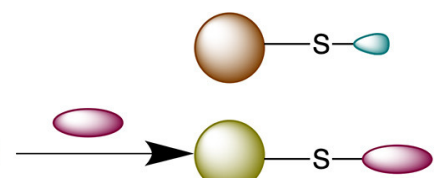<smiles>N=C1C(Cl)=CC=C([N+](=O)[O-])C1=NN</smiles><smiles>OSC1CCCCCC1</smiles>
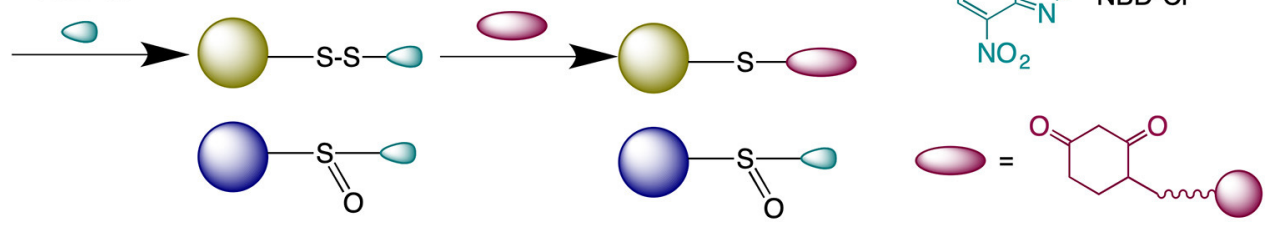

FIGURE 2 | Methods for persulfide labeling. (A) Modified-biotin switch assay. (B) Method based on thiol blocking (either with N-ethyl maleimide or iodoacetmide) followed by the reduction with dithiothreitol (DTT) or tris(2-carboxyethyl)phosphine (TCEP). (C) Low-pH quantitative thiol reactivity profiling approach. (D) Dimedone-switch method for persulfide labeling. NBD-Cl, 4-Chloro-7-nitrobenzofurazan.

leading to a gradual loss of function at the molecular, cellular, tissue, and organismal level. Nine cellular hallmarks of aging have been defined (López-Otín et al., 2013) that can be clustered into three distinct but interconnected sub-categories: (i) the primary hallmarks, which are the primary causes of cellular damage; (ii) the antagonistic hallmarks, involved in the compensatory system of response to cellular damage but can also be deleterious; and (iii) the integrative hallmarks that are the result of the two previous categories and are the late cellular and tissue response to the functional decline associated with aging. $\mathrm{H}_{2} \mathrm{~S}$ has been shown 


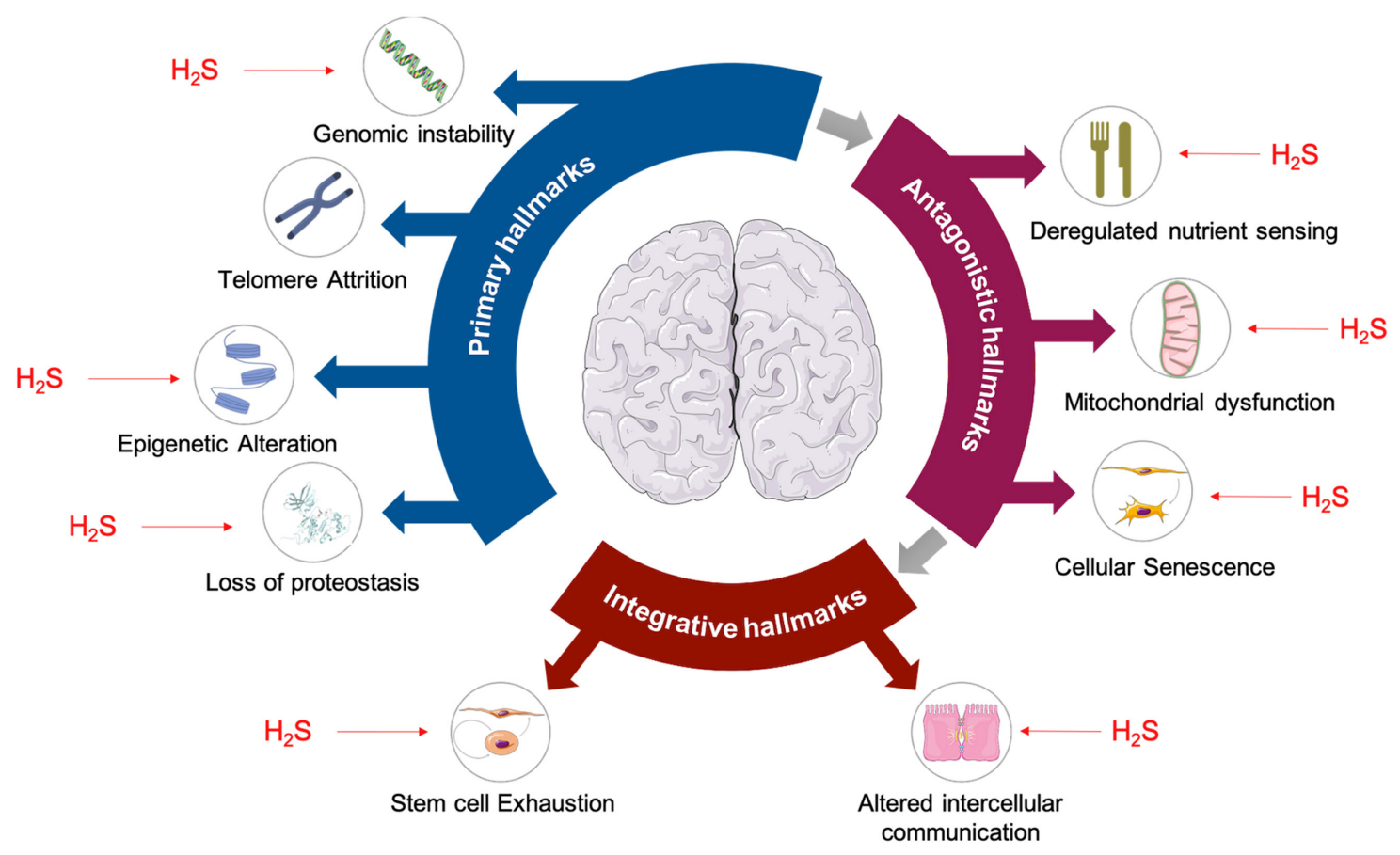

FIGURE 3 | Hallmarks of aging are affected by $\mathrm{H}_{2} \mathrm{~S}$. Primary hallmarks of aging shown to be affected by $\mathrm{H}_{2} \mathrm{~S}$ are: genomic instability (Szczesny et al., 2014; Zhao et al., 2014), epigenetic alterations (Suo et al., 2013; Rios et al., 2015), and loss of proteostasis (Liu et al., 2013; Fawcett et al., 2015). Antagonistic hallmarks of aging such as deregulated nutrient sensing (Xue et al., 2013; Ohno et al., 2015), mitochondrial dysfunction (Elrod et al., 2007; Sun et al., 2012), and cellular senescence (Yang et al., 2013; Zheng et al., 2014) are also affected by $\mathrm{H}_{2} \mathrm{~S}$. Finally, $\mathrm{H}_{2} \mathrm{~S}$ is also known to have effects on stem cell exhaustion (Liu et al., 2014a,b) and intracellular communication (Munaron et al., 2013), which are considered to be integrative hallmarks of aging.

to affect 8 out of 9 aging hallmarks (Zhang et al., 2013; Perridon et al., 2016); some examples being the prevention of genomic instability (by modifying MEK/ERK pathway which leads to Poly(ADP-ribose) polymerase 1 activation and DNA repair mechanisms promotion) (Zhao et al., 2014) and prevention of epigenetic alteration (by modulating Sirtuin 1, one of the three histone deacetylases involved in the regulation of longevity and/or healthy aging mammals) (Du et al., 2019) (Figure 3).

Two independent large-scale proteomic analyses revealed that CSE protein levels steadily decline as C. elegans age (Walther et al., 2015; Narayan et al., 2016). Conversely, a recent comprehensive analysis of 17 known lifespanextending interventions in mice, at the level of gene expression, identified CSE as a common denominator that is overexpressed (Tyshkovskiy et al., 2019).

Exposure to an $\mathrm{H}_{2} \mathrm{~S}$ - containing atmosphere significantly prolongs lifespan in wild type (WT) C. elegans without affecting its physiology. The ability of $\mathrm{H}_{2} \mathrm{~S}$ to induce a suspended animation-like state in mice (non-hibernating animals) (Blackstone et al., 2005) and the beneficial effects of $\mathrm{H}_{2} \mathrm{~S}$ on lifespan (Miller and Roth, 2007), originally demonstrated by Roth's group, created hope in designing ways to slow down aging and/or even putting humans into a hibernation-like state (Asfar et al., 2014). Although not as profound, similar results were obtained using the slow-releasing $\mathrm{H}_{2} \mathrm{~S}$ donor GYY4137 to which mimic physiological concentrations of $\mathrm{H}_{2} \mathrm{~S}$ more closely
(Qabazard et al., 2014); not only was the lifespan extended, but age-dependent changes were delayed in animals treated with GYY4137. Treatment with thiosulfate, which mimics beneficial effects of $\mathrm{H}_{2} \mathrm{~S}$, had a positive effect on C. elegans lifespan and correlated with high persulfidation levels in those animals (Zivanovic et al., 2019). Endogenous $\mathrm{H}_{2} \mathrm{~S}$ production also proved to be essential for lifespan extension in germline-deficient $C$. elegans mutants, where reduced transsulfuration activity caused by the knockdown of the $c b s-1$ gene significantly shortened the lifespan of germline-deficient mutants compared to WT (Wei and Kenyon, 2016).

Furthermore, CSE deficient mouse embryonic fibroblasts (MEF) have shown higher levels of oxidative stress in earlier passages and premature cell senescence in comparison with WT MEF. Oxidative stress resistance is dependent on the nuclear translocation of the antioxidant transcription factor Nrf2, which is enabled by persulfidation of its negative regulator Keap-1. Therefore, reduced $\mathrm{H}_{2} \mathrm{~S}$ production results in decreased Nrf2 activity and impaired antioxidant response in CSE deficient MEF cells (Yang et al., 2013).

One of the most reliable aspects of aging in mammals is vascular decline and impairment of angiogenesis, which significantly contributes to deterioration of human health with age and the development of age-related cardiovascular diseases. A recent study on aging mice displayed the importance of $\mathrm{H}_{2} \mathrm{~S}$ in restoring angiogenic potential later in life through 


\section{AGING, DISEASE}

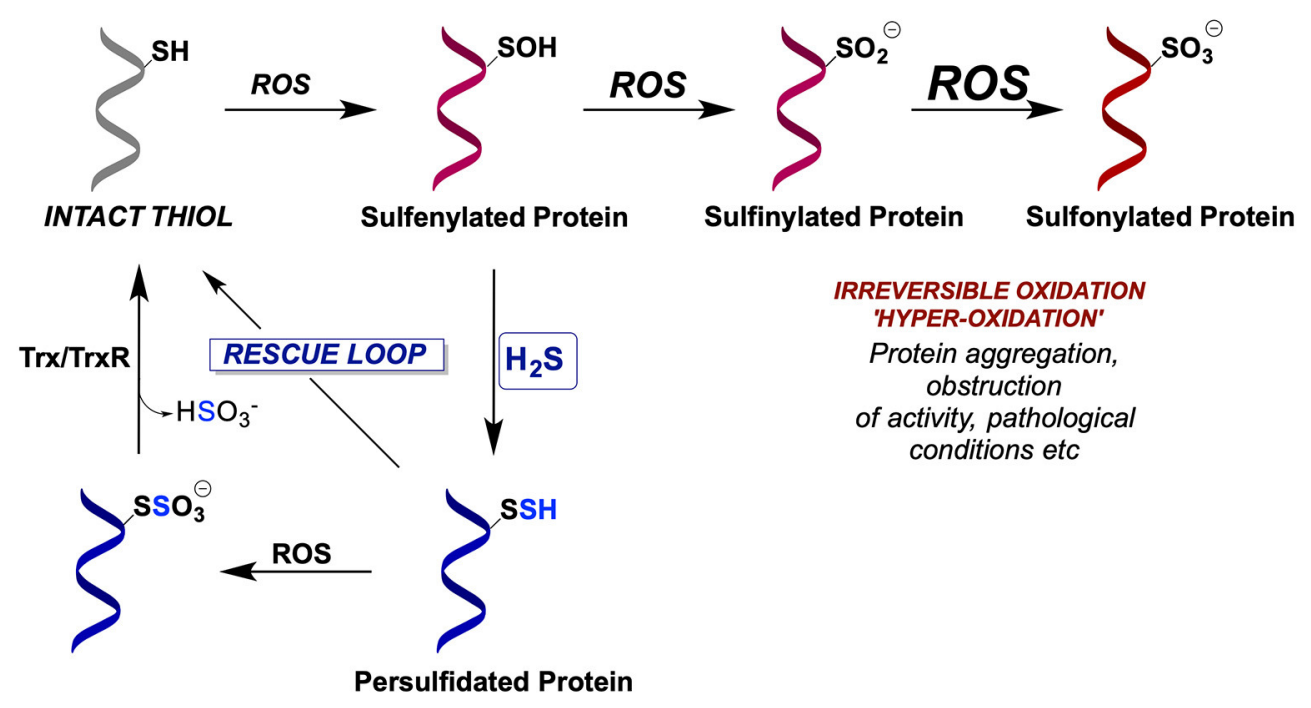

FIGURE 4 | Evolutionarily conserved mechanism for cellular protection by protein persulfidation. Due to their increased nucleophilicity, persulfides are better scavengers of ROS than cysteines resulting in the formation of S-sulfonates, which could potentially be reduced by thioredoxin/thioredoxin reductase system ( $\mathrm{rr} / \mathrm{Tr} \mathrm{R}$ ), restoring back the thiolates. In the absence of $\mathrm{H}_{2} \mathrm{~S}$, cysteine residues become irreversibly hyperoxidized leading to protein inactivation.

sirtuin-dependent deacetylase SIRT-1 pathway. The role of $\mathrm{H}_{2} \mathrm{~S}$ in cell senescence has also been demonstrated through the activation of the same pathway. The senescence of HUVEC cells (induced by oxidative stress or SIRT1 inhibition) was delayed upon $\mathrm{H}_{2} \mathrm{~S}$ treatment by activating the SIRT1 protein (Das et al., 2018; Longchamp et al., 2018).

In fact, the beneficial effects of dietary restriction (DR), acknowledged as one of the most promising interventions to improve health and extend longevity in wide variety of species, have been linked to $\mathrm{H}_{2} \mathrm{~S}$. Seminal work by Mitchell's group showed, using numerous model organisms including yeast, worms, flies and rodents, that endogenous $\mathrm{H}_{2} \mathrm{~S}$ levels increase upon different dietary restriction regimes (Hine et al., 2015). Furthermore, the lack of $\mathrm{H}_{2} \mathrm{~S}$ producing enzymes in flies, worms, and rodents abolishes the positive effects of DR, while the overexpression of these enzymes mimic the effects of DR without any dietary intervention (Kabil et al., 2011; Hine et al., 2015).

\section{PERSULFIDATION AS AN EVOLUTIONARILY CONSERVED ANTIAGING MECHANISM}

Questions to be answered are how can $\mathrm{H}_{2} \mathrm{~S}$ extend lifespan and whether there can be a unifying mechanism that might, in part, explain other beneficial effects assigned to $\mathrm{H}_{2} \mathrm{~S}$ ? Even though the persulfidation of cysteine residues seems like a logical answerhow can persulfidation extend lifespan? As aforementioned, $\mathrm{H}_{2} \mathrm{~S}$ cannot directly modify cysteine residues and an intermediary oxidation step is required. A drop in antioxidant defense mechanisms and increased ROS (mainly $\mathrm{H}_{2} \mathrm{O}_{2}$ ) production have long been postulated as key accelerators of aging (Balaban et al., 2005; Liochev, 2013; Sun et al., 2016). Our group recently proposed that persulfidation may be an evolutionary remnant of the times when life emerged in a sulfide-rich environment and that it represents the simplest way to resolve cysteine oxidation and protect proteins from oxidative damage (Zivanovic et al., 2019).

During oxidative stress cysteine residues get oxidized to sulfenic acids (Figure 4) representing an important signaling event for the cell to either start proliferating or to die (depending on the amount of $\mathrm{H}_{2} \mathrm{O}_{2}$ ) (Lo Conte and Carroll, 2013; Paulsen and Carroll, 2013). However, if left unreacted or exposed to further ROS, sulfenylated cysteines oxidize further to sulfinic $\left(\mathrm{P}-\mathrm{SO}_{2} \mathrm{H}\right)$ and sulfonic acids $\left(\mathrm{P}-\mathrm{SO}_{3} \mathrm{H}\right)$ (Chauvin and Pratt, 2017) which are generally considered irreversible [although some $\mathrm{P}-\mathrm{SO}_{2} \mathrm{H}$ could be reduced back to thiols (Akter et al., 2018)] and if buried deep in protein pockets, P-SOH can be stabilized and not easily reachable for the reduction (back to P-SH) (Paulsen and Carroll, 2013). However, the reaction of P-SOH with $\mathrm{H}_{2} \mathrm{~S}$ is $\sim 600$ times faster than with glutathione (Cuevasanta et al., 2015) and due to the small size of $\mathrm{H}_{2} \mathrm{~S}$ it can reach deep into protein structures; indeed, we have observed increased P-SSH formation as a response to $\mathrm{H}_{2} \mathrm{O}_{2}$ stress (Cuevasanta et al., 2015; Wedmann et al., 2016). Once formed, P-SSH can be reduced back to P-SH by the thioredoxin (Trx/TrxR) system (Dóka et al., 2016; Wedmann et al., 2016). Therefore, not only does this mechanism preserve cysteine residues but it also represents a novel form of a redox control of protein function. 
When oxidative stress persists (like in aging and many ROSrelated diseases), P-SSH can act as better scavengers of ROS than $\mathrm{P}-\mathrm{SH}$, resulting in the formation of $\mathrm{P}-\mathrm{SSO}_{3} \mathrm{H}$. The existence of an $\mathrm{S}-\mathrm{S}$ bond in $\mathrm{P}-\mathrm{SSH}$ makes this group a potential target for Trx to restore it to its native thiolate (Figure 4), hence instead of the accumulation of damaged hyperoxidized proteins (containing $\mathrm{P}-\mathrm{SO}_{3} \mathrm{H}$ ), the overall structure, function and half-life of thiolcontaining proteins can be preserved by their interim conversion to persulfides. We recently proved this mechanism showing that Trx is 2 orders of magnitude more efficient in cleaving cysteine S-sulfonate than cystine (Zivanovic et al., 2019).

Indeed, protein persulfidation was found to be conserved among different phyla and regna and was strongly dependent on the expression of the $\mathrm{H}_{2} \mathrm{~S}$ producing enzymes, most notably CSE. Protein persulfidation also showed a closely intertwined nature with sulfenylation, serving as a redox switch and rescuing cysteines from further oxidative damage in cells exposed to endogenous or exogenous $\mathrm{H}_{2} \mathrm{O}_{2}$. More importantly, a global increase in P-SSH formation (either pharmacologically with $\mathrm{H}_{2} \mathrm{~S}$ donors, or through dietary innervations, such as caloric restriction) proved to be protective against different ROS stressors and extended the lifespan of C. elegans (Zivanovic et al., 2019).

Somewhat surprisingly, protein persulfidation was found to decrease with aging in mice, rats, and humans. This effect was largely dependent on the decrease of some or all three $\mathrm{H}_{2} \mathrm{~S}$ producing enzymes. In the case of rat brains, a progressive loss of protein persulfidation from the age of 6-24 months was caused by the profound decrease in CSE, CBS, and MST protein expression levels. Furthermore, a drop in P-SSH levels in fibroblasts, collected from the same donor at two different time points of his life was matched with an increase of $\mathrm{P}-\mathrm{SO}_{2} \mathrm{H}$ levels (Zivanovic et al., 2019), further supporting the hypothesis of the overall protective effects of P-SSH in aging.

\section{CSE $\rightarrow \mathrm{H}_{2} \mathrm{~S} \rightarrow$ PSSH AXIS IN NEURODEGENERATION}

Neurodegenerative diseases (ND) are characterized by a progressive damage to neurons that results in compromised cognitive and/or motor functions. One of the common characteristics of ND is its age-dependency; for instance both Alzheimer's and Parkinson's diseases affect 10 and 2\% of the elderly population in the USA, respectively (Liu et al., 2017; Venkatachalam et al., 2020). Recent analysis of primate proteomes with different ND found that $16 \%$ of the analyzed proteins contained one or more cysteines unique to primates. Structural analysis of these proteins revealed that in a vast majority of the cases, these unique cysteine residues were surface-exposed, making them more susceptible to oxidation. The authors identified this group of proteins as "primate differential redoxome" showing that it contains multiple deterministic and susceptibility factors of major ND (Venkatachalam et al., 2020). In the light of the abovementioned facts that protein persulfidation acts as a general protective mechanism, it is tempting to speculate that there might be a causal link between aging-induced P-SSH decline and ND.

A common characteristic reported in the literature, found in even unrelated ND, is the loss/decrease of CSE which has been observed in human samples of Parkinson's, Huntington's, Alzheimer, and spinocerebellar ataxia 3 diseases, as well as in corresponding animal disease models (Vandiver et al., 2013; Paul et al., 2014; Snijder et al., 2015; Giovinazzo et al., 2021). A global decrease of protein persulfidation has also been observed for the latter three diseases (Snijder et al., 2015; Zivanovic et al., 2019; Giovinazzo et al., 2021). Besides a general protection, persulfidation could also represent a redox switch mechanism by which protein structure and/or function might be affected, and the search of these particular targets may pave the way to more targeted drug design toward ND therapeutics.

\section{Parkinson's Disease}

Parkinson's disease (PD) is a neurodegenerative disease caused by the death of dopamine-generating cells in the substantia nigra and one of the proteins considered responsible for this cell death is parkin (Shulman et al., 2011). Parkin is an E3 ubiquitin ligase with reactive cysteine residues that are susceptible to oxidative posttranslational modifications and modulate the protein's activity. For example, $S$-nitrosation of parkin inhibits its E3 ubiquitin ligase activity (Chung et al., 2004). It has been demonstrated recently that parkin can also be persulfidated at C59, C95, and C182 (Vandiver et al., 2013). The persulfidation of parkin, demonstrated even under basal conditions, leads to enzyme activation and clearance of damaged proteins (Figure 5A) (Vandiver et al., 2013). This has been observed in vivo, in samples from PD patients, which contained lower levels of persulfidated parkin, but increased levels of nitrosylated parkin (Vandiver et al., 2013).

In addition to parkin, the PD protein DJ-1 (also known as PARK7) is also known to be involved in the pathogenesis of PD. DJ-1 (also known as PARK7) undergoes oxidation to a sulfinic (Akter et al., 2018) and sulfonic acid (FernandezCaggiano et al., 2016), particularly at its Cys106. Sulfonylation of DJ-1 controls its intracellular localization and is implicated in protection against neuronal cell death (Canet-Avilés et al., 2004). We recently showed that DJ-1 undergoes protein persulfidation, which controls the levels of hyperoxidized form of this protein (Zivanovic et al., 2019). Whilst these data suggest that the use of $\mathrm{H}_{2} \mathrm{~S}$ releasing drugs could have potential in preventing PD progression they also warrant for more detailed studies on animal models where the pharmacological role of $\mathrm{H}_{2} \mathrm{~S}$ in $\mathrm{PD}$ could be assessed.

\section{Alzheimer's Disease}

Levels of $\mathrm{H}_{2} \mathrm{~S}$ in the brain of Alzheimer's disease (AD) patients have been found to be considerably low when compared to the healthy individuals (Eto et al., 2002; Giuliani et al., 2013) while pre-treatment with NaHS improved learning and memory deficits in rat AD model (Xuan et al., 2012). We recently showed that the tau protein binds to CSE increasing its $\mathrm{H}_{2} \mathrm{~S}$ producing activity. In addition, we observed that $\mathrm{H}_{2} \mathrm{~S}$ causes persulfidation of glycogen synthase kinase $3 \beta$ 


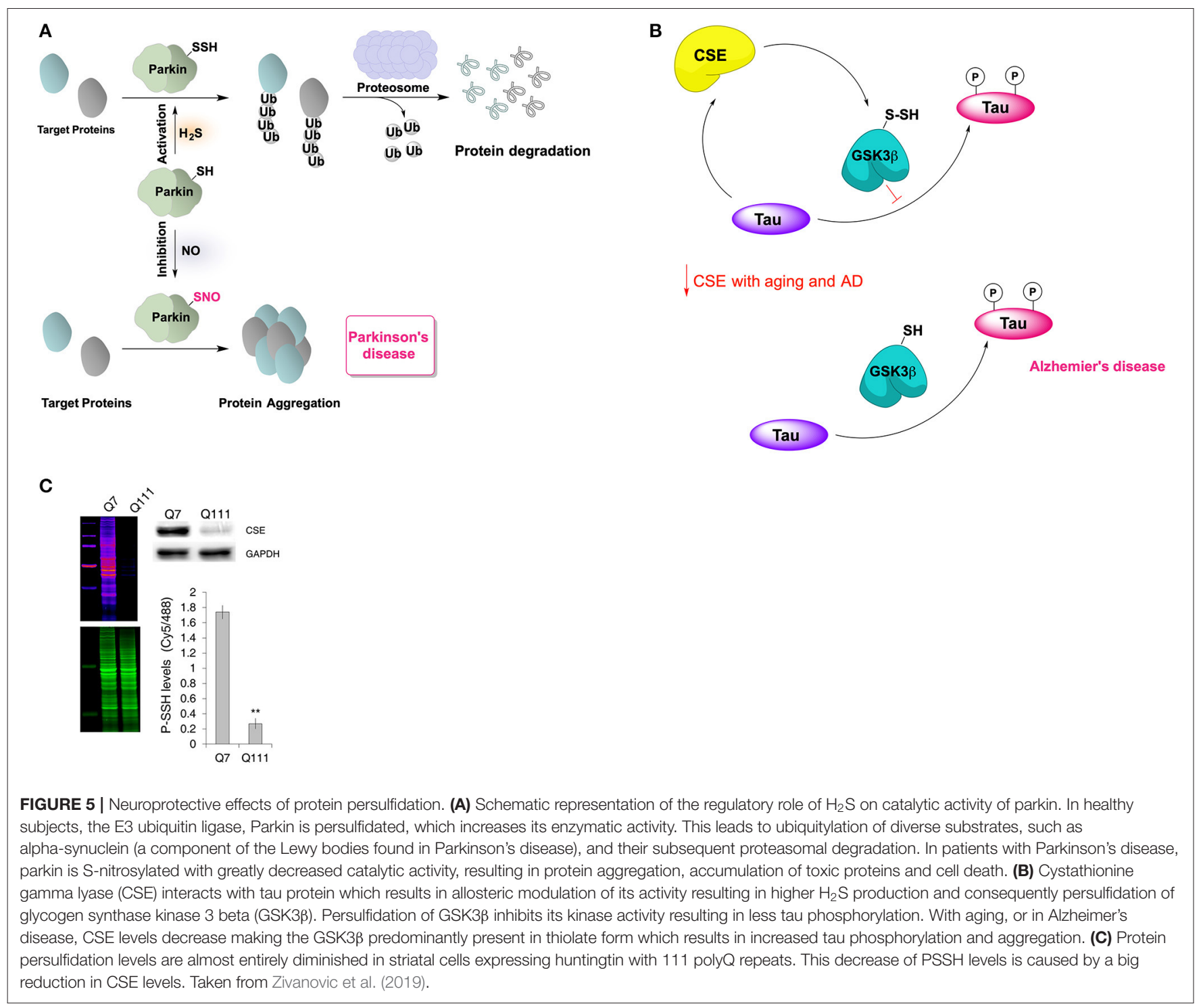

at C218, resulting in the loss of the enzyme's activity and diminishing tau phosphorylation (Giovinazzo et al., 2021). A decrease of CSE levels in aging brain and consequently the decrease of GSK3 $\beta$ persulfidation will result in an accumulation of phosphorylated tau and tau aggregation (Figure 5B). Interestingly, the treatment of $3 \mathrm{xTg}-\mathrm{AD}$ mice with GYY4137 restored global P-SSH levels and improved cognitive deficits.

In addition to GSK3 $\beta$ persulfidation, $\mathrm{H}_{2} \mathrm{~S}$ exhibited an inhibitory role on the gene and protein expression of BACE-1 (beta-site APP cleaving enzyme-1), a major $\beta$-secretase involved in amyloid beta $(A \beta)$ production (Zhang et al., 2011).

Further studies addressing the causal relationship between age-induced decrease of protein persulfidation and $\mathrm{AD}$ could help unraveling the potential drug targets for the $\mathrm{H}_{2} \mathrm{~S}$-releasing therapeutics but also identify eventual markers of this disease. Considering a high number of $\mathrm{AD}$ patients globally and documented $\mathrm{H}_{2} \mathrm{~S}$ releasing effects of some natural products
(Pluth et al., 2015), it could be worth testing them as supplementary therapy for AD patients.

\section{Poly-Q Diseases}

One of the most striking examples of how the dysregulation of the CSE $\rightarrow \mathrm{H}_{2} \mathrm{~S} \rightarrow \mathrm{P}-\mathrm{SSH}$ axis could lead to ND, is that of CSE knockout mice exhibiting Huntington's disease-like phenotype. Inspiring work by Snyder and Paul has demonstrated that CSE mutant mice display neurologic abnormalities, such as hind limb clasping which resembles mouse models of HD. Most importantly, in the striatum of human HD patients CSE levels were reduced by $85-90 \%$, with greater reductions being observed in patients that displayed more severe clinical manifestations of the disease (Paul et al., 2014).

Similar effects have been observed in another polyglutamine (polyQ) disease called spinocerebellar ataxia 3 (SCA3). In both a D. melanogaster model and humans the levels of CSE in the brain were reduced (Snijder et al., 2015) and we also showed 
that this results in diminished P-SSH levels. Similarly, striatal cells models of HD expressing huntingtin with 111 polyQ repeats displayed strikingly low global P-SSH levels (Figure 5C) (Zivanovic et al., 2019).

Paul, Snyder and co-workers observed that mutated huntingtin binds to transcription factor SP1, which is responsible for CSE expression, and that repressed ATF4 activity in HD further downregulates CSE levels (Paul et al., 2014; Sbodio et al., 2016). Treatment of HD cells with monensin, a Golgi stress inducer, resulted in activation of PERK-ATF4-CSE pathway and subsequent increase of $\mathrm{H}_{2} \mathrm{~S}$ and protein persulfidation leading to the better resistance of those cells to oxidants (Sbodio et al., 2018). Similarly, in D. melanogaster model of SCA3, overexpression of CSE rescued the disease phenotype, as manifested by decreased eye degeneration (Snijder et al., 2015).

\section{FUTURE DIRECTIONS}

The field of protein persulfidation is still very young but accumulating evidence suggests that this modification can be of great importance in understanding fundamental biological processes and in designing new therapeutics. There are few directions the field could be developing toward, in order to provide definitive answers about the role of protein persulfidation in neurodegeneration, some of which have been addressed in more details below.

\section{Persulfidome vs. Other Posttranslational Modifications in Brain}

To what extent are effects of protein persulfidation a consequence of a global protection (as described in Figure 3) and to what a consequence of a structure/function change induced by PSSH? These questions could be addressed by systematic proteomic analysis. Unlike S-nitrosylation, whose role in neuronal signaling and neurodegeneration has been extensively studied (Uehara et al., 2006; Cho et al., 2009; Nakamura et al., 2013; Seneviratne et al., 2016), the persulfidome changes in the brain, under healthy or disease conditions, have not been addressed. With the development of new targeted proteomics methods for protein sulfenylation (Fu et al., 2019), sulfinylation (Akter et al., 2018), cysteine oxidation and persulfidation (Zivanovic et al., 2019; Fu et al., 2020) it would be of interest to correlate the changes of all these cysteine modifications and other such as S-nitrosylation in brain aging and different ND models. Recent proteomic findings suggest that protein S-nitrosylation increases with aging of the brain, which is opposite to what has been reported for protein persulfidation (Kartawy et al., 2020). The cross-talk between Snitrosylation and P-SSH is also still an unanswered question (Filipovic et al., 2012), with examples like parkin where these two modifications have completely opposite effects on its activity (Chung et al., 2004; Vandiver et al., 2013).

Considering that many kinases and phosphatases have been reported to be persulfidated (Zivanovic et al., 2019; Fu et al., 2020), the effect(s) of P-SSH on protein phosphorylation should also be addressed. GSK3b is just one example of how protein persulfidation can control the phosphorylation of protein and prevent progression of the disease (Giovinazzo et al., 2021).

ND are characterized by the aggregation of many proteins that should normally undergo degradation via the two main catabolism pathways, the ubiquitin-proteasome system and the autophagy-lysosomal pathway (Le Guerroué and Youle, 2021). The effects of $\mathrm{H}_{2} \mathrm{~S}$ on both of those pathways have been reported in the literature. Future studies, based on brain persulfidome analysis should identify the targets that control these pathways and address their role in disease progression paving the way for the development of innovative therapeutic strategies that will permit targeted redox control of the cell metabolism and delay aging and disease progression.

\section{Development of $\mathrm{H}_{2} \mathrm{~S}$ Donors to Treat ND}

The use of water-soluble sodium salt of GYY4137 improved motor and cognitive deficits in AD mouse model (Giovinazzo et al., 2021), while administration of NaHS once a day for 3 months ameliorated memory deficits in another study (Liu et al., 2016). However, most of the studies done to date use inorganic sulfide salts as a source of $\mathrm{H}_{2} \mathrm{~S}$ and although they are good for proof-of-concept observation there is a need for a development of real $\mathrm{H}_{2} \mathrm{~S}$-releasing therapeutics. Several have entered clinical trials but mainly for treating inflammation (Wallace and Wang, 2015; Whiteman et al., 2015). Design of slow-releasing $\mathrm{H}_{2} \mathrm{~S}$ donors that could pass blood-brain barrier and be delivered could prove useful in treating some of the ND and ameliorating the general healthspan. Particularly interesting could be mitochondria-targeted $\mathrm{H}_{2} \mathrm{~S}$ donors (Le Trionnaire et al., 2014). For example, AP39 is known to generally improve mitochondrial bioenergetics (Gero et al., 2016; Etheridge et al., 2017; Fox et al., 2021) and supplementation of APP/PS1 mouse model of AD P39 improved mitochondrial dynamics, shifting from fission toward fusion, ameliorated their spatial memory deficits and reduced $A \beta$ deposition in their brains (Zhao et al., 2016).

In addition to the development of $\mathrm{H}_{2} \mathrm{~S}$ donors, the search for drugs that increase the expression of $\mathrm{H}_{2} \mathrm{~S}$ producing enzymes could be another interesting direction to go.

\section{AUTHOR CONTRIBUTIONS}

All authors listed have made a substantial, direct and intellectual contribution to the work, and approved it for publication.

\section{FUNDING}

This work was funded by the European Research Council (ERC) under the European Union's Horizon 2020 research and innovation programme (Grant Agreement No. 864921). 


\section{REFERENCES}

Abe, K., and Kimura, H. (1996). The possible role of hydrogen sulfide as an endogenous neuromodulator. J. Neurosci. 16, 1066-1071. doi: 10.1523/JNEUROSCI.16-03-01066.1996

Akter, S., Fu, L., Jung, Y., Conte, M., Lo, L., J. R., et al. (2018). Chemical proteomics reveals new targets of cysteine sulfinic acid reductase. Nat. Chem. Biol. 14, 995-1004. doi: 10.1038/s41589-018-0116-2

Aroca, A., Benito, J. M., Gotor, C., and Romero, L. C. (2017). Persulfidation proteome reveals the regulation of protein function by hydrogen sulfide in diverse biological processes in Arabidopsis. J. Exp. Bot. 68, 4915-4927. doi: $10.1093 /$ jxb/erx294

Asfar, P., Calzia, E., and Radermacher, P. (2014). Is pharmacological, H2Sinduced "suspended animation" feasible in the ICU? Crit. Care 18, 215-222. doi: 10.1186/cc13782

Balaban, R. S., Nemoto, S., and Finkel, T. (2005). Mitochondria, oxidants, and aging. Cell 120, 483-495. doi: 10.1016/j.cell.2005.02.001

Blackstone, E., Morrison, M., and Roth, M. B. (2005). H2S induces a suspended animation-like state in mice. Science 308:518. doi: 10.1126/science.1108581

Canet-Avilés, R. M., Wilson, M. A., Miller, D. W., Ahmad, R., McLendon, C., Bandyopadhyay, S., et al. (2004). The Parkinson's disease DJ-1 is neuroprotective due to cysteine-sulfinic acid-driven mitochondrial localization. Proc. Natl. Acad. Sci. U.S.A. 101, 9103-9108. doi: 10.1073/pnas.0402959101

Chauvin, J. P. R., and Pratt, D. A. (2017). On the reactions of thiols, sulfenic acids, and sulfinic acids with hydrogen peroxide. Angew. Chemie Int. Ed. 56, 6255-6259. doi: 10.1002/anie.201610402

Cho, D. H., Nakamura, T., Fang, J., Cieplak, P., Godzik, A., Gu, Z., et al. (2009). $\beta$-Amyloid-related mitochondrial fission and neuronal injury. Science 324, 102-105. doi: 10.1126/science.1171091

Chung, K. K. K., Thomas, B., Li, X., Pletnikova, O., Troncoso, J. C., Marsh, L., et al. (2004). S-Nitrosylation of parkin regulates ubiquitination and compromises Parkin's protective function. Science 304, 1328-1331. doi: 10.1126/science.1093891

Cuevasanta, E., Lange, M., Bonanata, J., Coitiño, E. L., Ferrer-Sueta, G., Filipovic, M. R., et al. (2015). Reaction of hydrogen sulfide with disulfide and Sulfenic acid to form the strongly Nucleophilic Persulfide. J. Biol. Chem. 290, 26866-26880. doi: 10.1074/jbc.M115.672816

Cuevasanta, E., Möller, M. N., and Alvarez, B. (2017). Biological chemistry of hydrogen sulfide and persulfides. Arch. Biochem. Biophys. 617, 9-25. doi: 10.1016/j.abb.2016.09.018

Das, A., Huang, G. X., Bonkowski, M. S., Longchamp, A., Li, C., Schultz, M. B., et al. (2018). Impairment of an endothelial NAD+-H2S signaling network is a reversible cause of vascular aging. Cell 173, 74-89.e20. doi: 10.1016/j.cell.2018.02.008

Dóka, É., Pader, I., Bíró, A., Johansson, K., Cheng, Q., Ballagó, K., et al. (2016). A novel persulfide detection method reveals protein persulfide- and polysulfide-reducing functions of thioredoxin and glutathione systems. Sci. Adv. 2:e1500968. doi: 10.1126/sciadv.1500968

Du, C., Lin, X., Xu, W., Zheng, F., Cai, J., Yang, J., et al. (2019). Sulfhydrated sirtuin1 increasing its deacetylation activity is an essential epigenetics mechanism of anti-atherogenesis by Hydrogen sulfide. Antioxidants Redox Signal. 30, 184-197. doi: 10.1089/ars.2017.7195

Elrod, J. W., Calvert, J. W., Morrison, J., Doeller, J. E., Kraus, D. W., Tao, L., et al. (2007). Hydrogen sulfide attenuates myocardial ischemia-reperfusion injury by preservation of mitochondrial function. Proc. Natl. Acad. Sci. U.S.A. 104, 15560-15565. doi: 10.1073/pnas.0705891104

Etheridge, T., Gaffney, C., Szewczyk, N., Torregrossa, R., Wood, M. E., and Whiteman, M. (2017). Mitochondria-targeting hydrogen sulfide donors prolong healthspan: lifespan ratio in Caenorhabditis elegans. Free Radic. Biol. Med. 112:51. doi: 10.1016/j.freeradbiomed.2017.10.067

Eto, K., Asada, T., Arima, K., Makifuchi, T., and Kimura, H. (2002). Brain hydrogen sulfide is severely decreased in Alzheimer's disease. Biochem. Biophys. Res. Commun. 293, 1485-1488. doi: 10.1016/S0006-291X(02)00422-9

Fan, K., Chen, Z., and Liu, H. (2020). Evidence that the ProPerDP method is inadequate for protein persulfidation detection due to lack of specificity. Sci. Adv. 6:eabb6477. doi: 10.1126/sciadv.abb6477
Fawcett, E. M., Hoyt, J. M., Johnson, J. K., and Miller, D. L. (2015). Hypoxia disrupts proteostasis in Caenorhabditis elegans. Aging Cell 14, 92-101. doi: 10.1111/acel.12301

Fernandez-Caggiano, M., Schröder, E., Cho, H. J., Burgoyne, J., BarallobreBarreiro, J., Mayr, M., et al. (2016). Oxidant-induced interprotein disulfide formation in cardiac protein DJ-1 occurs via an interaction with peroxiredoxin 2. J. Biol. Chem. 291, 10399-10410. doi: 10.1074/jbc.M115.699850

Filipovic, M. R. (2015). Persulfidation (S-sulfhydration) and H2S. Handb. Exp. Pharmacol. 230, 29-59. doi: 10.1007/978-3-319-18144-8_2

Filipovic, M. R., Miljkovic, J. L., Nauser, T., Royzen, M., Klos, K., Shubina, T., et al. (2012). Chemical characterization of the smallest S-nitrosothiol, HSNO; Cellular cross-talk of H2S and S-nitrosothiols. J. Am. Chem. Soc. 134, 12016-12027. doi: 10.1021/ja3009693

Filipovic, M. R., Zivanovic, J., Alvarez, B., and Banerjee, R. (2018). Chemical biology of H2S signaling through persulfidation. Chem. Rev. 118, 1253-1337. doi: 10.1021/acs.chemrev.7b00205

Fox, B. C., Slade, L., Torregrossa, R., Pacitti, D., Szabo, C., Etheridge, T., et al. (2021). The mitochondria-targeted hydrogen sulfide donor AP39 improves health and mitochondrial function in a $C$. elegans primary mitochondrial disease model. J. Inherit. Metab. Dis. 44, 367-375. doi: 10.1002/jimd.12345

Fu, L., Liu, K., Ferreira, R. B., Carroll, K. S., and Yang, J. (2019). Proteome-wide analysis of cysteine S-sulfenylation using a benzothiazine-based probe. Curr. Protoc. Protein Sci. 95:e76. doi: 10.1002/cpps.76

Fu, L., Liu, K., He, J., Tian, C., Yu, X., and Yang, J. (2020). Direct proteomic mapping of cysteine persulfidation. Antioxidants Redox Signal. 33, 1061-1076. doi: 10.1089/ars.2019.7777

Fu, M., Zhang, W., Wu, L., Yang, G., Li, H., and Wang, R. (2012). Hydrogen sulfide ( $\mathrm{H}$ 2S) metabolism in mitochondria and its regulatory role in energy production. Proc. Natl. Acad. Sci. U.S.A. 109, 2943-2948. doi: 10.1073/pnas.1115634109

Gao, X.-H., Krokowski, D., Guan, B.-J., Bederman, I., Majumder, M., Parisien, M., et al. (2015). Quantitative H2S-mediated protein sulfhydration reveals metabolic reprogramming during the integrated stress response. Elife 4:e10067. doi: $10.7554 /$ eLife.10067.039

Gero, D., Torregrossa, R., Perry, A., Waters, A., Le-Trionnaire, S., Whatmore, J. L., et al. (2016). The novel mitochondria-targeted hydrogen sulfide (H2S) donors AP123 and AP39 protect against hyperglycemic injury in microvascular endothelial cells in vitro. Pharmacol. Res. 113, 186-198. doi: 10.1016/j.phrs.2016.08.019

Giovinazzo, D., Bursac, B., Sbodio, J. I., Nalluru, S., Vignane, T., Snowman, A. M., et al. (2021). Hydrogen sulfide is neuroprotective in Alzheimer's disease by sulfhydrating GSK3 $\beta$ and inhibiting Tau hyperphosphorylation. Proc. Natl. Acad. Sci. U.S.A. 118:e2017225118. doi: 10.1073/pnas.2017225118

Giuliani, D., Ottani, A., Zaffe, D., Galantucci, M., Strinati, F., Lodi, R., et al. (2013). Hydrogen sulfide slows down progression of experimental Alzheimer's disease by targeting multiple pathophysiological mechanisms. Neurobiol. Learn. Mem. 104, 82-91. doi: 10.1016/j.nlm.2013.05.006

Greiner, R., Pálinkás, Z., Bäsell, K., Becher, D., Antelmann, H., Nagy, P., et al. (2013). Polysulfides link H2S to protein thiol oxidation. Antioxidants Redox Signal. 19, 1749-1765. doi: 10.1089/ars.2012.5041

Hine, C., Harputlugil, E., Zhang, Y., Ruckenstuhl, C., Lee, B. C., Brace, L., et al. (2015). Endogenous hydrogen sulfide production is essential for dietary restriction benefits. Cell 160, 132-144. doi: 10.1016/j.cell.2014.11.048

Ida, T., Sawa, T., Ihara, H., Tsuchiya, Y., Watanabe, Y., Kumagai, Y., et al. (2014). Reactive cysteine persulfides and S-polythiolation regulate oxidative stress and redox signaling. Proc. Natl. Acad. Sci. U.S.A. 111, 7606-7611. doi: 10.1073/pnas.1321232111

Kabil, H., Kabil, O., Banerjee, R., Harshman, L. G., and Pletcher, S. D. (2011). Increased transsulfuration mediates longevity and dietary restriction in Drosophila. Proc. Natl. Acad. Sci. U.S.A. 108, 16831-16836. doi: 10.1073/pnas.1102008108

Kabil, O., Zhou, Y., and Banerjee, R. (2006). Human cystathionine $\beta$-synthase is a target for sumoylation. Biochemistry 45, 13528-13536. doi: 10.1021/bi0615644

Kartawy, M., Khaliulin, I., and Amal, H. (2020). Systems biology reveals reprogramming of the S-nitroso-proteome in the cortical and striatal regions of mice during aging process. Sci. Rep. 10:13913. doi: 10.1038/s41598-020-70383-6 
Kimura, Y., Mikami, Y., Osumi, K., Tsugane, M., Oka, J. I., and Kimura, H. (2013). Polysulfides are possible $\mathrm{H} 2 \mathrm{~S}$-derived signaling molecules in rat brain. FASEB J. 27, 2451-2457. doi: 10.1096/fj.12-226415

Lange, M., Ok, K., Shimberg, G. D., Bursac, B., Markó, L., Ivanović-Burmazović, I., et al. (2019). Direct zinc finger protein persulfidation by $\mathrm{H} 2 \mathrm{~S}$ is facilitated by Zn2+. Angew. Chemie Int. Ed. 58, 7997-8001. doi: 10.1002/anie.201900823

Le Guerroué, F., and Youle, R. J. (2021). Ubiquitin signaling in neurodegenerative diseases: an autophagy and proteasome perspective. Cell Death Differ. 28, 439-454. doi: 10.1038/s41418-020-00667-x

Le Trionnaire, S., Perry, A., Szczesny, B., Szabo, C., Winyard, P. G., Whatmore, J. L., et al. (2014). The synthesis and functional evaluation of a mitochondriatargeted hydrogen sulfide donor, (10-oxo-10-(4-(3-thioxo-3H-1,2-dithiol-5yl)phenoxy)decyl) triphenylphosphonium bromide (AP39). Medchemcomm 5, 728-736. doi: 10.1039/C3MD00323J

Liochev, S. I. (2013). Reactive oxygen species and the free radical theory of aging. Free Radic. Biol. Med. 60, 1-4. doi: 10.1016/j.freeradbiomed.2013.02.011

Liu, D., Wang, Z., Zhan, J., Zhang, Q., Wang, J., Zhang, Q., et al. (2014a). Hydrogen sulfide promotes proliferation and neuronal differentiation of neural stem cells and protects hypoxia-induced decrease in hippocampal neurogenesis. Pharmacol. Biochem. Behav. 116, 55-63. doi: 10.1016/j.pbb.2013.11.009

Liu, Y., Deng, Y., Liu, H., Yin, C., Li, X., and Gong, Q. (2016). Hydrogen sulfide ameliorates learning memory impairment in APP/PS1 transgenic mice: a novel mechanism mediated by the activation of Nrf2. Pharmacol. Biochem. Behav. 150-151, 207-216. doi: 10.1016/j.pbb.2016.11.002

Liu, Y., Yang, R., Liu, X., Zhou, Y., Qu, C., Kikuiri, T., et al. (2014b). Hydrogen sulfide maintains mesenchymal stem cell function and bone homeostasis via regulation of $\mathrm{Ca}(2+)$ channel sulfhydration. Cell Stem Cell 15, 66-78. doi: 10.1016/j.stem.2014.03.005

Liu, Y. Y., Nagpure, B. V., Wong, P. T. H., and Bian, J. S. (2013). Hydrogen sulfide protects SH-SY5Y neuronal cells against d-galactose induced cell injury by suppression of advanced glycation end products formation and oxidative stress. Neurochem. Int. 62, 603-609. doi: 10.1016/j.neuint.2012.12.010

Liu, Z., Zhou, T., Ziegler, A. C., Dimitrion, P., and Zuo, L. (2017). Oxidative stress in neurodegenerative diseases: from molecular mechanisms to clinical applications. Oxid. Med. Cell. Longev. 2017, 1-11. doi: 10.1155/2017/2525967

Lo Conte, M., and Carroll, K. S. (2013). The redox biochemistry of protein sulfenylation and sulfinylation. J. Biol. Chem. 288, 26480-26488. doi: 10.1074/jbc.R113.467738

Longchamp, A., Mirabella, T., Arduini, A., MacArthur, M. R., Das, A., TreviñoVillarreal, J. H., et al. (2018). Amino acid restriction triggers angiogenesis via GCN2/ATF4 regulation of VEGF and H2S production. Cell 173, 117-129.e14. doi: 10.1016/j.cell.2018.03.001

Longen, S., Richter, F., Köhler, Y., Wittig, I., Beck, K.-F., and Pfeilschifter, J. (2016). Quantitative persulfide site identification (qPerS-SID) reveals protein targets of H2S releasing donors in mammalian cells. Sci. Rep. 6:29808. doi: $10.1038 /$ srep29808

López-Otín, C., Blasco, M. A., Partridge, L., Serrano, M., and Kroemer, G. (2013). The hallmarks of aging. Cell 153:1194. doi: 10.1016/j.cell.2013.05.039

Miller, D. L., and Roth, M. B. (2007). Hydrogen sulfide increases thermotolerance and lifespan in Caenorhabditis elegans. Proc. Natl. Acad. Sci. U.S.A. 104, 20618-20622. doi: 10.1073/pnas.0710191104

Munaron, L., Avanzato, D., Moccia, F., and Mancardi, D. (2013). Hydrogen sulfide as a regulator of calcium channels. Cell Calcium 53, 77-84. doi: 10.1016/j.ceca.2012.07.001

Mustafa, A. K., Gadalla, M. M., Sen, N., Kim, S., Mu, W., Gazi, S. K., et al. (2009). H2S signals through protein S-sulfhydration. Sci. Signal. 2, ra72-ra72. doi: 10.1126/scisignal.2000464

Nagahara, N., Ito, T., Kitamura, H., and Nishino, T. (1998). Tissue and subcellular distribution of mercaptopyruvate sulfurtransferase in the rat: confocal laser fluorescence and immunoelectron microscopic studies combined with biochemical analysis. Histochem. Cell Biol. 110, 243-250. doi: $10.1007 / \mathrm{s} 004180050286$

Nakamura, T., Tu, S., Akhtar, M. W., Sunico, C. R., Okamoto, S., and Lipton, S. A. (2013). Aberrant protein S-nitrosylation in neurodegenerative diseases. Neuron 78, 596-614. doi: 10.1016/j.neuron.2013.05.005

Narayan, V., Ly, T., Pourkarimi, E., Murillo, A. B., Gartner, A., Lamond, A. I., et al. (2016). Deep proteome analysis identifies age-related processes in C. elegans. Cell Syst. 3, 144-159. doi: 10.1016/j.cels.2016.06.011
Ohno, K., Okuda, K., and Uehara, T. (2015). Endogenous S-sulfhydration of PTEN helps protect against modification by nitric oxide. Biochem. Biophys. Res. Commun. 456, 245-249. doi: 10.1016/j.bbrc.2014.11.066

Olson, K. R., and Straub, K. D. (2016). The role of hydrogen sulfide in evolution and the evolution of hydrogen sulfide in metabolism and signaling. Physiology 31, 60-72. doi: 10.1152/physiol.00024.2015

Pan, J., and Carroll, K. S. (2013). Persulfide reactivity in the detection of protein $S$ -sulfhydration. ACS Chem. Biol. 8, 1110-1116. doi: 10.1021/cb4001052

Patel, B. H., Percivalle, C., Ritson, D. J., Duffy, C. D., and Sutherland, J. D. (2015). Common origins of RNA, protein and lipid precursors in a cyanosulfidic protometabolism. Nat. Chem. 7, 301-307. doi: 10.1038/nchem.2202

Paul, B. D., Sbodio, J. I., Xu, R., Vandiver, M. S., Cha, J. Y., Snowman, A. M., et al. (2014). Cystathionine $\gamma$-lyase deficiency mediates neurodegeneration in Huntington's disease. Nature 508, 96-100. doi: 10.1038/nature13136

Paul, B. D., and Snyder, S. H. (2012). H2S signalling through protein sulfhydration and beyond. Nat. Rev. Mol. Cell Biol. 13, 499-507. doi: 10.1038/nrm3391

Paul, B. D., and Snyder, S. H. (2015). $\mathrm{H}_{2} \mathrm{~S}$ : A novel gasotransmitter that signals by sulfhydration. Trends Biochem. Sci. 40, 687-700. doi: 10.1016/j.tibs.2015.08.007

Paulsen, C. E., and Carroll, K. S. (2013). Cysteine-mediated redox signaling: chemistry, biology, and tools for discovery. Chem. Rev. 113, 4633-4679. doi: $10.1021 / \mathrm{cr} 300163 \mathrm{e}$

Peng, Y. J., Makarenko, V. V., Nanduri, J., Vasavda, C., Raghuraman, G., Yuan, G., et al. (2014). Inherent variations in co-h2s-mediated carotid body O 2 sensing mediate hypertension and pulmonary edema. Proc. Natl. Acad. Sci. U.S.A. 111, 1174-1179. doi: 10.1073/pnas.1322172111

Perridon, B. W., Leuvenink, H. G. D., Hillebrands, J. L., Van Goor, H., and Bos, E. M. (2016). The role of hydrogen sulfide in aging and age-related pathologies. Aging 8, 2264-2289. doi: 10.18632/aging.101026

Pluth, M. D., Bailey, T. S., Hammers, M. D., Hartle, M. D., Henthorn, H. A., and Steiger, A. K. (2015). Natural products containing hydrogen sulfide releasing moieties. Synlett 26, 2633-2643. doi: 10.1055/s-0035-1560638

Qabazard, B., Li, L., Gruber, J., Peh, M. T., Ng, L. F., Kumar, S. D., et al. (2014). Hydrogen sulfide is an endogenous regulator of aging in Caenorhabditis elegans. Antioxidants Redox Signal. 20, 2621-2630. doi: 10.1089/ars.2013.5448

Rios, E. C. S., Szczesny, B., Soriano, F. G., Olah, G., and Szabo, C. (2015). Hydrogen sulfide attenuates cytokine production through the modulation of chromatin remodeling. Int. J. Mol. Med. 35, 1741-1746. doi: 10.3892/ijmm.2015.2176

Sbodio, J. I., Snyder, S. H., and Paul, B. D. (2016). Transcriptional control of amino acid homeostasis is disrupted in Huntington's disease. Proc. Natl. Acad. Sci. U.S.A. 113, 8843-8848. doi: 10.1073/pnas.1608264113

Sbodio, J. I., Snyder, S. H., and Paul, B. D. (2018). Golgi stress response reprograms cysteine metabolism to confer cytoprotection in Huntington's disease. Proc. Natl. Acad. Sci. U.S.A. 115, 780-785. doi: 10.1073/pnas.1717 877115

Sen, N., Paul, B. D., Gadalla, M. M., Mustafa, A. K., Sen, T., Xu, R., et al. (2012). Hydrogen sulfide-linked sulfhydration of NF-кB mediates its antiapoptotic actions. Mol. Cell 45, 13-24. doi: 10.1016/j.molcel.2011.10.021

Seneviratne, U., Nott, A., Bhat, V. B., Ravindra, K. C., Wishnok, J. S., Tsai, L. H., et al. (2016). S-nitrosation of proteins relevant to Alzheimer's disease during early stages of neurodegeneration. Proc. Natl. Acad. Sci. U.S.A. 113, 4152-4157. doi: $10.1073 /$ pnas.1521318113

Shulman, J. M., De Jager, P. L., and Feany, M. B. (2011). Parkinson's disease: genetics and pathogenesis. Annu. Rev. Pathol. Mech. Dis. 6, 193-222. doi: 10.1146/annurev-pathol-011110-130242

Snijder, P. M., Baratashvili, M., Grzeschik, N. A., Leuvenink, H. G. D., Kuijpers, L., Huitema, S., et al. (2015). Overexpression of cystathionine $\gamma$-lyase suppresses detrimental effects of spinocerebellar ataxia type 3. Mol. Med. 21, 758-768. doi: 10.2119/molmed.2015.00221

Sun, N., Youle, R. J., and Finkel, T. (2016). The mitochondrial basis of aging. Mol. Cell 61, 654-666. doi: 10.1016/j.molcel.2016.01.028

Sun, W. H., Liu, F., Chen, Y., and Zhu, Y. C. (2012). Hydrogen sulfide decreases the levels of ROS by inhibiting mitochondrial complex IV and increasing SOD activities in cardiomyocytes under ischemia/reperfusion. Biochem. Biophys. Res. Commun. 421, 164-169. doi: 10.1016/j.bbrc.2012.03.121

Suo, R., Zhao, Z. Z., Tang, Z. H., Ren, Z., Liu, X., Liu, L. S., et al. (2013). Hydrogen sulfide prevents $\mathrm{H} 2 \mathrm{O} 2$-induced senescence in human umbilical vein endothelial cells through SIRT1 activation. Mol. Med. Rep. 7, 1865-1870. doi: $10.3892 / \mathrm{mmr} .2013 .1417$ 
Szabõ, C. (2007). Hydrogen sulphide and its therapeutic potential. Nat. Rev. Drug Discov. 6, 917-935. doi: 10.1038/nrd2425

Szabó, C., and Papapetropoulos, A. (2011). Hydrogen sulphide and angiogenesis: mechanisms and applications. Br. J. Pharmacol. 164, 853-865. doi: 10.1111/j.1476-5381.2010.01191.x

Szczesny, B., Módis, K., Yanagi, K., Coletta, C., Le Trionnaire, S., Perry, A., et al. (2014). AP39, a novel mitochondria-targeted hydrogen sulfide donor, stimulates cellular bioenergetics, exerts cytoprotective effects and protects against the loss of mitochondrial DNA integrity in oxidatively stressed endothelial cells in vitro. Nitric Oxide Biol. Chem. 41, 120-130. doi: 10.1016/j.niox.2014.04.008

Szijártó, I. A., Markó, L., Filipovic, M. R., Miljkovic, J. L., Tabeling, C., Tsvetkov, D., et al. (2018). Cystathionine $\gamma$-lyase-produced hydrogen sulfide controls endothelial no bioavailability and blood pressure. Hypertension 71, 1210-1217. doi: 10.1161/HYPERTENSIONAHA.117.10562

Teng, H., Wu, B., Zhao, K., Yang, G., Wu, L., and Wang, R. (2013). Oxygen-sensitive mitochondrial accumulation of cystathionine $\beta$-synthase mediated by Lon protease. Proc. Natl. Acad. Sci. U.S.A. 110, 12679-12684. doi: 10.1073/pnas.1308487110

Tyshkovskiy, A., Bozaykut, P., Borodinova, A. A., Gerashchenko, M. V., Ables, G. P., Garratt, M., et al. (2019). Identification and application of gene expression signatures associated with lifespan extension. Cell Metab. 30, 573-593.e8. doi: 10.1016/j.cmet.2019.06.018

Uehara, T., Nakamura, T., Yao, D., Shi, Z. Q., Gu, Z., Ma, Y., et al. (2006). S-Nitrosylated protein-disulphide isomerase links protein misfolding to neurodegeneration. Nature 441, 513-517. doi: 10.1038/nature04782

Vandiver, M. S., Paul, B. D., Xu, R., Karuppagounder, S., Rao, F., Snowman, A. M., et al. (2013). Sulfhydration mediates neuroprotective actions of parkin. Nat. Commun. 4:1626. doi: $10.1038 /$ ncomms 2623

Vasas, A., Dóka, É., Fábián, I., and Nagy, P. (2015). Kinetic and thermodynamic studies on the disulfide-bond reducing potential of hydrogen sulfide. Nitric oxide Biol. Chem. 46, 93-101. doi: 10.1016/j.niox.2014.12.003

Venkatachalam, N., Bakavayev, S., Engel, D., Barak, Z., and Engel, S. (2020). Primate differential redoxome (PDR) - a paradigm for understanding neurodegenerative diseases. Redox Biol. 36:101683. doi: 10.1016/j.redox.2020.101683

Vitvitsky, V., Miljkovic, J. L., Bostelaar, T., Adhikari, B., Yadav, P. K., Steiger, A. K., et al. (2018). Cytochrome c Reduction by H 2 S Potentiates Sulfide Signaling. ACS Chem. Biol. 13, 2300-2307. doi: 10.1021/acschembio.8b00463

Wallace, J. L., and Wang, R. (2015). Hydrogen sulfide-based therapeutics: exploiting a unique but ubiquitous gasotransmitter. Nat. Rev. Drug Discov. 14, 329-345. doi: 10.1038/nrd4433

Walther, D. M., Kasturi, P., Zheng, M., Pinkert, S., Vecchi, G., Ciryam, P., et al. (2015). Widespread proteome remodeling and aggregation in aging C. elegans. Cell 161, 919-932. doi: 10.1016/i.cell.2015.03.032

Wedmann, R., Bertlein, S., Macinkovic, I., Böltz, S., Miljkovic, J. L., Muñoz, L. E., et al. (2014). Working with "H2S": facts and apparent artifacts. Nitric Oxide 41, 85-96. doi: 10.1016/j.niox.2014.06.003

Wedmann, R., Onderka, C., Wei, S., Szijártó, I. A., Miljkovic, J. L., Mitrovic, A., et al. (2016). Improved tag-switch method reveals that thioredoxin acts as depersulfidase and controls the intracellular levels of protein persulfidation. Chem. Sci. 7, 3414-3426. doi: 10.1039/C5SC04818D

Wei, Y., and Kenyon, C. (2016). Roles for ROS and hydrogen sulfide in the longevity response to germline loss in Caenorhabditis elegans. Proc. Natl. Acad. Sci. U.S.A. 113, E2832-E2841. doi: 10.1073/pnas.15247 27113

Whiteman, M., Perry, A., Zhou, Z., Bucci, M., Papapetropoulos, A., Cirino, G., et al. (2015). "Phosphinodithioate and phosphoramidodithioate hydrogen sulfide donors," in Handbook of Experimental Pharmacology, Vol. 230, 337-363. doi: 10.1007/978-3-319-18144-8_17
Whiteman, M., and Winyard, P. G. (2011). Hydrogen sulfide and inflammation: the good, the bad, the ugly and the promising. Expert Rev. Clin. Pharmacol. 4, 13-32. doi: 10.1586/ecp.10.134

Xuan, A., Long, D., Li, J., Ji, W., Zhang, M., Hong, L., et al. (2012). Hydrogen sulfide attenuates spatial memory impairment and hippocampal neuroinflammation in beta-amyloid rat model of Alzheimer's disease. J. Neuroinflammation 9:687. doi: 10.1186/1742-2094-9-202

Xue, R., Hao, D. D., Sun, J. P., Li, W. W., Zhao, M. M., Li, X. H., et al. (2013). Hydrogen sulfide treatment promotes glucose uptake by increasing insulin receptor sensitivity and ameliorates kidney lesions in type 2 diabetes. Antioxidants Redox Signal. 19, 5-23. doi: 10.1089/ars.2012.5024

Yadav, P. K., Martinov, M., Vitvitsky, V., Seravalli, J., Wedmann, R., Filipovic, M. R., et al. (2016). Biosynthesis and reactivity of cysteine persulfides in signaling. J. Am. Chem. Soc. 138, 289-299. doi: 10.1021/jacs.5b10494

Yang, G., Wu, L., Jiang, B., Yang, W., Qi, J., Cao, K., et al. (2008). H2S as a physiologic vasorelaxant: hypertension in mice with deletion of cystathionine $\gamma$-lyase. Science 322, 587-590. doi: 10.1126/science.1162667

Yang, G., Zhao, K., Ju, Y., Mani, S., Cao, Q., Puukila, S., et al. (2013). Hydrogen sulfide protects against cellular senescence via s-sulfhydration of keap1 and activation of Nrf2. Antioxidants Redox Signal. 18, 1906-1919. doi: 10.1089/ars.2012.4645

Zhang, D., Macinkovic, I., Devarie-Baez, N. O., Pan, J., Park, C.-M., Carroll, K. S., et al. (2014). Detection of protein S-sulfhydration by a tag-switch technique. Angew. Chemie Int. Ed. 53, 575-581. doi: 10.1002/anie.201305876

Zhang, H., Gao, Y., Zhao, F., Dai, Z., Meng, T., Tu, S., et al. (2011). Hydrogen sulfide reduces mRNA and protein levels of beta-site amyloid precursor protein cleaving enzyme 1 in PC12 cells. Neurochem. Int. 58, 169-175. doi: 10.1016/j.neuint.2010.11.010

Zhang, Y., Tang, Z.-H., Ren, Z., Qu, S.-L., Liu, M.-H., Liu, L.-S., et al. (2013). Hydrogen sulfide, the next potent preventive and therapeutic agent in aging and age-associated diseases. Mol. Cell. Biol. 33, 1104-1113. doi: 10.1128/MCB.01215-12

Zhao, F. L., Fang, F., Qiao, P. F., Yan, N., Gao, D., and Yan, Y. (2016). AP39, a mitochondria-targeted hydrogen sulfide donor, supports cellular bioenergetics and protects against Alzheimer's disease by preserving mitochondrial function in APP/PS1 mice and neurons. Oxid. Med. Cell. Longev. 2016, 1-19. doi: 10.1155/2016/8360738

Zhao, K., Ju, Y., Li, S., Altaany, Z., Wang, R., and Yang, G. (2014). S-sulfhydration of MEK1 leads to PARP-1 activation and DNA damage repair. EMBO Rep. 15, 792-800. doi: 10.1002/embr.201338213

Zheng, M., Qiao, W., Cui, J., Liu, L., Liu, H., Wang, Z., et al. (2014). Hydrogen sulfide delays nicotinamide-induced premature senescence via upregulation of SIRT1 in human umbilical vein endothelial cells. Mol. Cell. Biochem. 393, 59-67. doi: 10.1007/s11010-014-2046-y

Zivanovic, J., Kouroussis, E., Kohl, J. B., Adhikari, B., Bursac, B., SchottRoux, S., et al. (2019). Selective persulfide detection reveals evolutionarily conserved antiaging effects of S-sulfhydration. Cell Metab. 30, 1152-1170.e13. doi: 10.1016/j.cmet.2019.10.007

Conflict of Interest: The authors declare that the research was conducted in the absence of any commercial or financial relationships that could be construed as a potential conflict of interest.

Copyright $\odot 2021$ Petrovic, Kouroussis, Vignane and Filipovic. This is an open-access article distributed under the terms of the Creative Commons Attribution License (CC $B Y)$. The use, distribution or reproduction in other forums is permitted, provided the original author(s) and the copyright owner(s) are credited and that the original publication in this journal is cited, in accordance with accepted academic practice. No use, distribution or reproduction is permitted which does not comply with these terms. 